\author{
Olga Lomakina \\ Doctor of Philological Sciences, Professor, \\ St. Tikhon's Orthodox University, \\ Peoples' Friendship University of Russia \\ (Moskow, Russia) \\ e-mail: rusoturisto07@mail.ru
}

\title{
LEO TOLSTOY'S PHRASEOLOGICAL DICTIONARY: PRINCIPLES OF CREATING A VOCABULARY, BUILDING A DICTIONARY, THE DIFFICULTIES OF A LEXICOGRAPHIC DESCRIPTION, THE STUCTURE OF A DICTIONARY ENTRY
}

\begin{abstract}
This paper deals with the description and peculiarities of the metalanguage in Leo Tolstoy's phraseological dictionary being compiled. The purpose of this paper is to show how materials are selected, and how a dictionary entry is made. The research methods include the descriptive analytical method, and the functional contextological method. The topicality of the research is related to the need for a lexicographic description of Leo Tolstoy's language, because to date this writer's language has not been described lexicographically. The creation of Leo Tolstoy's phraseological dictionary will make it possible to study the dynamic development of not only the entire phraseological corpus but also specific phraseological units, as well as to provide insight into the writer's linguistic persona as a whole. The continuous sampling method helps to the fullest extent possible and systematically represent the corpus of phraseological units, proverbs, and winged words, as well as complement the data on the 19th century language. The choice of heading forms stems from verbal use rather than the linguistic tradition used in lexicography. The headword principle for the arrangement of entries simplifies 'reading' of the dictionary as searching of a relevant entry is thus made faster. There being a list of the phraseological corpus described at the end of the dictionary, also makes it easier to work therewith. The breakdown of the phraseological material into sections (e.g. proverbs, winged words, fixed similes) is accounted for by the heterogeneity of Leo Tolstoy's language phraseology. The dictionary entry structure is traditional. In most cases reliance on the existing phraseographic publications helps formulate the meaning part, however, when doing so the context dependent meaning as well as the author's self-definition must be borne in mind. The illustrative part includes examples from texts of different styles and genres; the arrangement of this illustrative material is in chronological order, which makes it possible to see how the author's preferences have been changing, which creative period the use of this unit is characteristic of, how the writer's creative potential manifested itself in the course of creating transforms. Where there are any phraseological unit variants, all the recorded variants including their type definition and example illustration are listed. The informative comment is an optional element of the dictionary entry containing historical and etymological, linguoculturological, and biographic information. The dictionary entry concludes with a list of lexicographic publications that have recorded this unit indicating the publication and the page number, which makes it possible to obtain information of the lexicographic record and description time, and the writer's influence over its entry into the standard language.
\end{abstract}

Key words: Phraseography, L. N. Tolstoy's language, dictionary, language of the writer, author's lexicography. 


\author{
О. В. Ломакина \\ Доктор филологических наук, профессор \\ Православный Свято-Тихоновский гуманитарный университет, \\ Российский университет дружбы народов \\ (Москва, Россия) \\ e-mail: rusoturisto07@mail.ru
}

\title{
«ФРАЗЕОЛОГИЧЕСКИЙ СЛОВАРЬ ЯЗЫКА Л. Н. ТОЛСТОГО»: ПРИНЦИПЫ СОЗДАНИЯ СЛОВНИКА, ПОСТРОЕНИЕ СЛОВАРЯ, ТРУДНОСТИ ЛЕКСИКОГРАФИЧЕСКОГО ОПИСАНИЯ, СТРУКТУРА СЛОВАРНОЙ СТАТЬИ
}

\begin{abstract}
Аннотация. Статья посвящена описанию и особенностям метаязыка создаваемого «Фразеологический словарь языка Л. Н. Толстого». Цель статьи - показать, как проводится отбор материала, как строится словарная статья. Методы проведённого исследования включают описательно-аналитический метод, функционально-контекстологический метод. Актуальность проводимого исследования связана с необходимостью лексикографического описания языка Л. Н. Толстого, поскольку до настоящего времени язык этого писателя лексикографически не описан. Создание «Фразеологического словаря Л. Н. Толстого» позволит рассмотреть динамическое развитие не только всего фразеологического корпуca, но и конкретных ФЕ, а также охарактеризовать языковую личность писателя в целом. Приём сплошной выборки помогает представить фонд фразеологических единиц (ФЕ), паремий и крылатых выражений (КВ) наиболее полно, упорядоченно, дополнить сведения о языке XIX в. Выбор формы заголовочных единиц объясняется речевым использованием, а не языковой, распространённой в лексикографии традицией. Стержневой принцип расположения материала упрощает «чтение» словаря: поиск интересующей единицы идёт быстрее. Наличие в конце словаря перечня описанного фразеологического корпуса также способствует удобству работы с ним. Распределение фразеологического материала по разделам (например, паремии, КВ, устойчивые сравнения) объясняется разнородностью состава фразеологии языка Л. Н. Толстого. Структура словарной статьи носит традиционный характер. Опора на существующие фразеографические издания в большинстве случаев помогает сформировать область значения, однако при формулировке области значения необходимо учитывать контекстуально обусловленное значение, а также авторскую самодефиницию. Иллюстративная часть включает примеры из текстов различных стилей и жанров, расположение иллюстративного материала проводится в хронологическом порядке, что позволяет увидеть, как менялись авторские предпочтения, для какого периода творчества характерно употребление данной единицы, как выражался творческий потенциал писателя при создании трансформов. При наличии вариантов ФЕ приводятся все зафиксированные варианты с определением их типов и иллюстрацией примеров. Информативный комментарий является факультативным элементом словарной статьи и содержит сведения историко-этимологического, лингвокультурологического, биографического характера. Словарную статью венчает перечисление зафиксировавших единицу лексикографических изданий с точным указанием издания и номера страницы, что позволяет получить сведения о времени лексикографической фиксации и описания и влияния писателя на факт вхождения в литературный язык.
\end{abstract}

Ключевые слова: Фразеография, язык Л.Н. Толстого, словарь, язык писателя, авторская лексикография. 


\section{ВВЕДЕНИЕ}

Современная лексикография представляет собой многостороннее образование, развивающееся в теоретическом и практическом направлениях, отвечающее запросам адресата относительно различной информации об описываемой единице. Сегодня можно с уверенностью заявить, что словарное дело имеет большой и необычайно полезный опыт в представлении языковых единиц различных уровней языка, который, безусловно, должен учитываться при создании новых словарных проектов. Вместе с тем остаются актуальными не только теоретические вопросы (например, выбор терминов авторская лексикография vs писательская лексикография, детская лексикография, компьютерная лексикография; разработка метаязыка современного словаря, критериев разграничения понятий тип и жанр словаря) (Lomakina 2018: 41-45), но и практические наработки, связанные с упорядочением и словарным описанием языка писателей, тексты которых не подвергались комплексному лексикографическому анализу.

Актуальность данной работы связана с тем, что язык Л. Н. Толстого, изучавшийся в течение долгого времени, не подвергался подробному лексикографическому описанию, которое позволит всецело проанализировать особенности идиостиля писателя. Нами было доказано, что фразеология является чертой идиостиля Л. Н. Толстого, на основании чего можно говорить о необходимости разработки понятия фразеологическая система языка писателя (Lomakina 2017). Наблюдения относительно фразеологической системы писателя можно сделать на основе фразеографических данных.

\section{ОБЗОР ЛИТЕРАТУРЫ}

Хотя фразеологические особенности языка Л. Н. Толстого были многократно рассмотрены, до настоящего момента не существует фразеологического словаря языка этого писателя. Вместе с тем предпринимались некоторые попытки фразеографического описания языка Л. Н. Толстого.

Охарактеризуем те лексикографические издания и анонсы, где материалом описания служат фразеоресурсы языка.

«Частотный жанрово-стилистический словарь фразеологии Л. Н. Толстого» (составитель - Ю. В. Архангельская) создан при помощи специальной компьютерной программы. Цель - «дать достаточно полные сведения о количественном составе в произведениях Л. Н. Толстого, что предполагает полную инвентаризацию и систематизацию ФЕ в относительно замкнутой системе (ограниченной текстами) с учетом жанровостилистической ее дифференциации» (Arkhangelskaya 2008: 6). В словаре фиксируются все ФЕ, в том числе и иноязычные, оформленные в нетранслитерированном виде. Параметризация проходит по следующим признакам: 1) начальная форма ФЕ; 2) контекстуальное употребление; 3) варианты (если есть), 4) структурный тип; 5) сфера использования (стилистическая характеристика ФЕ); 6) название произведения; 7) год создания произведения; 8) номер жанровой группы; 9) название жанровой группы, к которой относится данное произведение или текст (1 - художественные произведения; 2 - публицистические произведения; 3 - учебно-методические тексты; 4 - эпистолярные тексты; 5 - дневниковые тексты); 10) жанр произведения. Структура словаря трехчастна: 1) алфавитночастотный список $\Phi Е$; 2) частотный список $Ф Е ; 3)$ статистическая структура словаря (Arkhangelskaya 2008). 
Словарь Ю. В. Архангельской «Лев Толстой в языке и речи» относится к авторской лексикографии. По словам составителя, основной массив составляют инновации «индивидуально-авторские новообразования, т. е. слова и выражения, которые впервые употребил тот или иной автор» (Arhangel'skaja, 2016: 4). Ю. В. Архангельская объединяет в словарь речевые и языковые инновации Л. Н. Толстого. Для удобства материал разделён на четыре раздела, в каждом из которых - отдельная группа единиц: 1) камерные (семейные) инновации Л. Н. Толстого; 2) общеупотребительные инновации Л. Н. Толстого; 3 ) устойчивые высказывания о Л. Н. Толстом; 4) избранные афоризмы Л. Н. Толстого. С точки зрения описания фразеологического материала в большей степени интересны первый и второй раздел, где собран обширный материал. Принцип организации - алфавитный, зона толкований содержит функционально-стилистические и эмоциональнооценочные пометы (Arhangel'skaja 2016).

«Словарь галлицизмов в романе Л. Н. Толстого “Война и мир”», по замыслу составителя М. Р. Очкасовой, может служить ключом к пониманию языковой личности писателя, поскольку «словарная статья нацелена на то, чтобы показать место определённой лексемы или словосочетания в лексико-фразеологической системе, образуемой текстом романа» (Ochkasova 2005: 223). Словарная статья включает: 1) заглавное слово, словосочетание, $\Phi Е ; 2)$ словарную дефиницию; 3) контекст функционирования в романе; 4) семантизацию, которая содержит определение смыслового содержания в контексте, коннотацию. Таким образом, благодаря подобному описанию можно представить анализируемые галлицизмы в языковой системе: особенности сочетаемости, системные отношения.

Представленные лексикографические разработки фразеологии языка Л. Н. Толстого отличаются разнообразием в выборе метаязыка, что, в первую очередь, обусловлено целью словаря, а также принципами отбора материала. Следовательно, разнится и информативный потенциал словарных опытов. Так, «Частотный жанрово-стилистический словарь фразеологии Л. Н. Толстого», составленный Ю.В. Архангельской, содержит статистические данные об употреблении ФЕ в конкретном произведении, в определенном жанре, а также сведения о частотности использования писателем любой ФЕ, имеющейся в базе данных. Кроме того, словарь дополняет сведения о тенденциях фразеоупотребления со 2-й половины XIX до 00-х гг. XX в., служит для характеристики фразеологии языка не только Л. Н. Толстого, но и других художников слова в синхронном и диахронном аспектах. В лексикографических анонсах М. Р. Очкасовой ФЕ выступают одним из элементов словарного описания, наряду со словами и словосочетаниями, что помогает представить языковую личность Л. Н. Толстого в её структурной организации. Несомненно, словари дифференциального типа, к каким относится «Словарь галлицизмов в романе Л. Н. Толстого "Война и мир”», являются составляющим элементом в создании словаря языка писателя.

\section{МЕТОДЫ ИССЛЕДОВАНИЯ}

Методы проведённого исследования включают описательно-аналитический метод, предусматривающий непосредственное наблюдение анализируемых явлений в конкретных речевых условиях, систематизацию и обобщение фразеосредств, функционирующих в языке определённого писателя (что нашло отражение в исследованиях следующих учёных: А. Г. Ломова, описывающего фразеоресурурсы языка А. Н. Островского; Е. И. Сели- 
верстовой, посвящённых фразеологии языка Н. С. Лескова; В. М. Мокиенко и К. П. Сидоренко, изучавших фразеологическую составляющую языка И. А. Крылова, А. С. Грибоедова, А. С. Пушкина); функционально-контекстологический метод - при отслеживании закономерностей отбора и использования писателем фразеологического материала русского и иностранных языков (впервые было представлено в работах И. В. Гюббенет, Г. В. Колшанского, А. В. Кунина, А. М. Мелерович); приём сплошной выборки, получивший обоснование в работах по корпусной лингвистике, - при отборе языкового материала из «Полного собрания сочинений» Л. Н. Толстого и лексикографических источников.

\section{РЕЗУЛЬТАТЫ И ДИСКУССИЯ}

Подготовка «Фразеологического словаря Л.Н. Толстого» может стать одним из первых этапов создания словаря языка Л.Н. Толстого, поскольку фразеология языка этого писателя является значимой частью всего фразеологического фонда русского языка и отличается многообразием типов, вариантностью форм, созданием окказиональных фразеологизмов, а в целом характеризует язык определённого времени. Фразеологические единицы (ФЕ), будучи единицами когнитивного уровня, отражают особенности языковой личности великого писателя и являются одним из путей понимания всего творческого наследия Л.Н. Толстого.

Язык Л. Н. Толстого даёт богатый материал, иллюстрирующий потенциальные возможности как нетрансформированного, так и трансформированного использования $\Phi Е$, на основании чего в корпус «Фразеологического словаря Л. Н. Толстого» включаются не только распространенные в литературном языке ФЕ, пословицы, КЕ, но и различные примеры их «нестандартного» употребления (term of A. N. Baranov, D. O Dobrovolskiy). Особый интерес для исследователей языка представляют камерная (авторская) фразеология, а также окказиональные ФЕ, позволяющие показать особенности авторского понимания и переосмысления фразеологического материала.

О направлениях работы, связанных с подготовкой «Фразеологического словаря языка Л. Н. Толстого», нами было сказано ранее (Lomakina 2008: 2018). Приёмом сплошной выборки был установлен фразеологический корпус единиц, используемых писателем в текстах различных стилей и жанров. Например, жанр народных драм и народных рассказов демонстрирует разговорную «стихию»: содержит преимущественно разговорные и просторечные ФЕ, различные жанры паремий, что позволяет представить разговорный язык 2-й пол. XIX в. Популярность французского языка и хорошее знание писателем иностранных языков обусловило включение в тексты ФЕ-ИВ, что позволило выделить сквозные единицы, встречающиеся в различных текстах. Дневники, репрезентующие авторское мировидение, философские взгляды Л. Н. Толстого, изобилуют КЕ, представленными как на русском, так и на иностранных языках.

С учётом разнородности фразеологического состава языка Л. Н. Толстого, многотысячного объёма примеров контекстуального употребления - иллюстративного материала, а также руководствуясь простотой поиска интересующей единицы, мы сочли оправданным и целесообразным внутри «Фразеологического словаря языка Л. Н. Толстого» отдельно представить ФЕ, включая паремии и крылатые выражения (КВ), употребляемые писателем, в виде специальных разделов и подразделов, что отражается и в словарных статьях при помощи помет (Посл.; Примета; Франц.; КВ; Пушкинизм и др.): 1. Соб- 
ственно ФЕ. 2. Паремии: пословицы, приметы, присловья и под. 3. Крылатика: БФЕ, остальные КВ. 4. Камерные ФЕ. 5. ФЕ - иноязычные вкрапления (ИВ).

При составлении «Фразеологического словаря языка Л.Н. Толстого» мы опираемся на положительный опыт теории лексикографии, на традиции как отечественных, так и зарубежных фразеографов. Однако перед составителями различных фразеологических словарей стоит ряд нерешенных и дискуссионных вопросов. Несомненно, главными из них являются следующие: что включать в словник, и какой принцип построения словарной статьи выбрать. Во многом ответы на эти вопросы лежат в плоскости задач, которые приходится решать фразеографам. При работе над данным словарём обозначились некоторые проблемы.

Источником отбора материала послужило «Полное собрание сочинений» (ПСС) Л. Н. Толстого в 90 т., изданное в 1928-1958 гг. Это издание содержит ряд погрешностей технического плана, в некоторых случаях требуется расшифровка текстов, уточнение написания некоторых слов. От аутентичности некоторых цитат зависит правильность заголовочной единицы, в частности - паремии. Иногда при многочисленном переписывании в текст закрадывались описки, которые не были исправлены в ПСС: Доброта завяжет крепче долга / дома (?) (“Dnevniki” 1884), Скотины / Скопил - таракана да жуколища; а nосуды - крест да пуговиць ("Zapiski Khristianina”).

Словник «Фразеологического словаря языка Л.Н. Толстого» составлен с опорой на существующие лексикографические источники, с учётом которых происходила верификация полученного фразеологического корпуса.

Словарная статья - ведущий жанр лексикографии, основная структурная единица словаря. Традиционно словарная статья включает заголовочную единицу и её описание, имеет компактное, синтаксически организуемое пространство - занимает абзац.

Словарная статья «Фразеологического словаря языка Л. Н. Толстого» включает т. н. языковую и речевую зоны и состоит из следующих элементов: стержневой элемент, заголовочная единица (лемма, вокабула), экспрессивно-стилистическая помета (если есть), словарная дефиниция, иллюстративная часть, информативный комментарий. Используются различные шрифтовые выделения и символы.

Особое место занимают единицы, не включённые в общеизвестные словари, обладающие признаками ФЕ / паремии; при исследовании языка писателя их фиксация обязательна. В том случае, если описываемая единица уже содержится в лексикографических источниках, то словарь называется с указанием страницы, т. е. происходит чёткая паспортизация. Используется специальное графическое обозначение $\mathbf{v}$.

Распределение материала производится по стержневому принципу. Выбранный стержневой принцип позволяет читателю быстрее найти необходимую единицу. Стержневые компоненты располагаются в алфавитном порядке. Например, при описании пареМИЙ: КАКОЙ ПАЛЕЦ НИ УКУСИ, ВСЁ БОЛЬНО. СМ. ПАЛЕЦ; ПЕТУХИ КРИЧАТ РАНО К ВЕСЁЛОЙ НОЧИ. СМ. ПЕТУХ. В том случае, если в ФЕ нельзя выделить стержневое слово (при сочинительной связи компонентов), то по первому знаменательному слову: НИ ТО НИ СЁ. См. ТО. При лексикографическом описании ФЕ - ИВ используется алфавитный порядок: A BON ENTENDEUR - SALUT! Франц. Благо тому, кто умеет слушать! ALL IS RIGHT, WHAT IS RIGHT. Англ. Посл. Все хорошо, что хорошо. ФЕ с одной фразеолексемой (например, ВЫЦАРАПАТЬ ГЛАЗА, ПОДНИМАТЬ / ПОДНЯТЬ ГЛАЗА) объединены в пределах словарной статьи ГЛАЗ, т. к. соматизмы, наряду с зоонимами, назва- 
ниями стихий, цветами и под., являются наиболее продуктивными, благодаря чему словарная статья становится более информативной. ФЕ-омонимы приводятся в отдельных словарных статьях и сопровождаются индексами: 3А ГЛАЗА $\mathbf{A}^{\mathbf{1}}$, 3А ГЛАЗ $\mathbf{A}^{\mathbf{2}}$. Все значения многозначных ФЕ даются только в том случае, если они используются писателем.

При лексикографической обработке фразеологических ресурсов языка одной из проблем, связанных с интерпретацией обрабатываемого материала, является вопрос вариантности анализируемых единиц, для которых, в отличие от слова, варьирование частотно. Давая определение фразеологических вариантов, отечественные лингвисты подчеркивают тождественность их значения и образной основы, относительную стабильность синтаксической структуры и различия в компонентном составе и/или морфологических характеристиках компонентов.

Очевидно, что для выявления всего многообразия вариантов важна точная паспортизация единиц, которая позволит разделить синтагматические и парадигматические изменения, увидеть всё многообразие существующих вариантов, это докажет динамический характер фразеологии. Кроме того, важно выбрать типологию вариантов, систему знаков, так как «<..> при таком подходе отражается реальная жизнь фразеологизма, описываются все его речевые потенции и специфика употребления в конкретном языке» (Melerovich, Mokienko 1997: 4). Вместе с тем фразеотворчество опирается на структурносемантические модели, которые свойственны тому или иному языку.

На начальном этапе мы проводили проверку правильности заголовочной единицы. Обычно выбор заголовочной единицы опирается на данные словарей, где эта единица была зафиксирована. Однако даже в авторитетных изданиях («Пословицы русского народа» В. И. Даля; «Словарь русских пословиц и поговорок» В.П. Жукова; «Фразеологический словарь русского литературного языка к. XVIII - н. XX» под ред. А. И. Фёдорова; «Большой словарь крылатых слов и выражений русского языка» В. П. Беркова, В.М. Мокиенко, С.Г. Шулежковой и др.) одновременно могут приводиться два параллельно существующих варианта. Поэтому составитель, руководствуясь контекстуальным употреблением, решает, какую единицу выбрать в качестве заголовочной. Например, паремиографическое описание нескольких паремий в «Словаре пословиц и поговорок языка Л. Н. Толстого» будет отличаться от более распространенного: заголовочной паремией станет Яйца курииу учат для иллюстрации следующего примера:

Но графиня оттолкнула дочь и подошла к графу.

- Mon cher, mы распорядись, как надо... «Я ведь не знаю этого», - сказала она, виновато опуская глаза.

- Яйца... яйща курицу учат... - сквозь счастливые слезы проговорил граф и обнял жену, которая рада была скрыть на его груди свое пристыженное лищо («Война и мир», т. III, ч. 2, гл. XVI; 11: 172).

Здесь мы опираемся не только на паспортизацию единицы в словарях, но и на авторское употребление пословицы, являющейся единицей паремиологического пространства писателя (Lomakina, Makarova 2015).

Для определения типологии вариантов в качестве рабочей мы используем классификацию, предложенную А. М. Мелерович и В. М. Мокиенко. Данная типология составлена с учётом языковых реалий - примеров речевого употребления, поэтому является наиболее адаптированной для фразеографического описания языка писателя. Для указания на преобразование используется обозначение $\boldsymbol{B a p u a н m , ~ к о т о р о е ~ р а с п о л а г а е т с я ~ п о ~ ц е н - ~}$ 
тру строки и отделяет нетрансформированные единицы от трансформов, при этом указывается тип трансформации.

Семантизацию описываемого фразеологического корпуса наиболее точно помогают привести словари (особенно «Словарь пословиц и поговорок» В. П. Жукова). Б.А. Ларин отмечал необходимость тщательной разработки словарной статьи, говорил о толкованиях, которые не являются просто повтором узуального значения (Larin 2003: 651-652), для чего следует учитывать авторскую самодефиницию - особый способ раскрытия смыслового содержания ФЕ, паремий, КВ в тексте, к чему Л.Н. Толстой прибегает в некоторых случаях (Lomakina 2018: 62-67).

Рукодствуясь положительным опытом составителей «Словаря автобиографической трилогии М. Горького, толкование мы проводили в зависимости от того, как определяются ФЕ:

1) субстантивно: ШУт ГОРОхОВЫЙ. Экспрес. Нелепо, старомодно, безвкусно, смешно одетый человек. С женою-то его рядом поставьте: то-то шут гороховый («Война и мир», т. II, ч. 3, гл. XV; 10: 200).

2) предикативно: УДАРЯТь / УДАРИТь ПО РУКАМ. Разг. Договориться о чём-то, заключить сделку. Федор Иваныч. Сосватал, сосватал, и по рукам ударили. Только не пили («Плоды просвещения», д. 3, явл. 9).

3) адвербиально: НЕ БЛИЖНИй СВЕТ. Прост. Не близко, достаточно далеко. Акулина. Что плохое загадывать. Рано еще. Тоже не ближний свет. Пока что... («От ней все качества», д. 1, явл. 1).

4) атрибутивно: НИ ЖИВ НИ МЁРТВ. Сильно напуган. Он любил сльлшать за собой этот дикий крик пьяных голосов: «пошел! пошел!» тогда как уж и так нельзя было ехать шибче; любил вытянуть больно по шее мужика, который и так ни жни, ни мёртв сторонился от него («Война и мир», т. II, ч. 5, гл. XVI).

5) как самостоятельные предложения (ФЕ-УФ): ШАПКАМИ ЗАКИДАЕМ. Прост. Пренебр. Быстро и легко победим. - Да, это: мы шапками закидаем, мы нашли то, чего ищет Европа! Все это я знаю, но, извините меня, вы знаете ли все, что сделано в Евpone по вопросу об устройстве рабочих? («Анна Каренина», ч. 3, гл. XXVII).

В отличие от общеязыковых словарей, но в соответствии с фразеографической традицией грамматические пометы отсутствуют. Иллюстративная часть состоит из примеров контекстуального употребления с учётом хронологии творчества писателя и сопровождается точной паспортизацией по цитируемому источнику (ПСС). Иллюстративный материал приводится курсивом.

Каждую из словарных статей сопровождает справочный аппарат, содержащий ссылку на лексикографический источник с указанием номера страницы. Важным элементом справочного аппарата является информативный комментарий. Информативный комментарий может включать этимологический анализ. Скрупулёзное изучение истории устойчивых оборотов позволило В. М. Мокиенко разработать алгоритм поэтапного историко-этимологического анализа ФЕ и паремий, который позволяет «произвести отсев однозначно сомнительных интерпретаций либо обосновать сомнительность в истинности освященных традицией «этнографических» толкований» (Mokienko 2010: 120). Такое всестороннее рассмотрение устойчивых словосочетаний в их исторических и межъязыковых связях дало ему возможность опровергнуть многие существовавшие версии об исконно- 
сти оборота, традиционно связывавшегося с русскими реалиями, или, наоборот, продемонстрировать национальную специфику калькированного выражения.

Другим видом информативного комментария может стать лингвокультурологический анализ, один из этапов историко-этимологического анализа ФЕ, когда лексикографы обращаются к культурологическим, этнографическим, мифологическим и другим фактам, наряду с лингвистическими, для расшифровки фразеологического этимона, дает возможность опровергнуть версии об исконности оборота, традиционно связывавшегося с русскими реалиями, или, наоборот, продемонстрировать национальную специфику калькированного выражения. Таким образом, лингвокультурологический анализ ФЕ опирается не только на идеи лингвокультурологии, получившей развитие в конце XX - н. XXI вв., но и на этимологические данные.

Опираясь на существующие фразеографические издания, включающие лингвокультурологический анализ, необходимо выработать новый алгоритм при составлении авторских словарей с учетом тенденций современной лексикографии. Исходя из иллюстративного материала, составитель должен определиться, какие словарные статьи будут включать историко-этимологическую справку. На наш взгляд, нет смысла слепо переносить данные из общеизвестных фразеологических словарей.

В языке Л.Н. Толстого особое место занимает камерная фразеология: анковский пирог, отправиться в большое путешествие, пятый хомут, муаровый жилет, зеленая палочка, муравейное братство, комната под сводами, архитектор виноват, вырезушчатая перегородка и под. Камерная (авторская) фразеология - устойчивые обороты, возникающие и функционирующие в узком кругу лиц, в пределах семьи (Rudnev 1979: 75) служат способом идентификации в пределах мини-социума.

Несомненно, словарные статьи, посвященные описанию камерных ФЕ, должны включать информативный комментарий. Поскольку автором камерных ФЕ был сам писатель или члены его семьи, то при создании словарной статьи необходимо привлекать не только текстологию Л.Н. Толстого, но и воспоминания, переписку членов семьи, единомышленников. Все это позволит решить ряд лексикографических задач: толковать значение (семантизация нередко происходит в контексте), подготовить историкоэтимологическую справку.

\section{ЗАКЛЮЧЕНИЕ}

«Фразеологический словарь языка Л. Н. Толстого» призван упорядочить, ФЕ, паремии, КВ, используемые писателем, назвать рекуррентные языковые единицы, выявить особенности жанрового и дискурсивного использования их писателем, изучить языковую индивидуальность, охарактеризовать ИКМ, представить масштаб словесного творчества Л. Н. Толстого. Этот словарь расширит данные об истории русского литературного языка XIX в., отразит существующие тогда литературные нормы, выявит языковые предпочтения писателя, что необходимо в связи с работой над «Словарем русского языка XIX в.». «Фразеологический словарь языка Л. Н. Толстого» можно использовать и в учебных целях: в процессе преподавания фразеологии как части курса «Современный русский язык». 


\section{REFERENCES}

Arhangel'skaja, Ju. V. (2016) Lev Tolstoj v jazyke i rechi: Slovar' innovacij (leksika, frazeologija, aforistika) (Leo Tolstoy in Language and Speech: Vocabulary of Innovations (vocabulary, phraseology, aphoristics)). Tula: TPPO.

Arhangel'skaja, Ju.V. (2008) Frazeologija v diskurse L.N. Tolstogo (Phraseology in the discourse of L. N. Tolstoy). Tula: Tul'skij poligrafist.

Larin, B. A. (2003) O rabote nad novymi slovarjami (About working on new dictionaries) // Larin B. A. Filologicheskoe nasledie: sb. statej. Sankt-Peterburg: SPbGU, 649-655.

Lomakina, O. V. (2008) Principy otbora materiala pri sostavlenii «Frazeologicheskogo slovarja L.N. Tolstogo» (Principles of material selection in the compilation of the «Phraseological dictionary L. N. Tolstoy»). Frazeologizm i slovo v nacional'no-kul'turnom diskurse. Moskva: «Izdatel'stvo "Jelpis"», 507-509.

Lomakina, O. V. (2018) Frazeologija v tekste: funkcionirovanie i idiostil' (Phraseology in the text: functioning and idiostyle). Moskva: RUDN.

Lomakina, O. V. (2017) Frazeologija kak cherta jazykovoj lichnosti L.N. Tolstogo (Phraseology as Leo Tolstoy linguistic personality trait). Svět v obrazech a ve frazeologii. Praga: Univerzita Karlova, Pedagogická fakulta, 145-168.

Lomakina O. V., Makarova, A.S. (2015) Var'irovanie ustojchivyh fraz: ot teorii frazeografii k praktike upotreblenija (Modification of the Steady Phrases: from the Theory of the Phraseography to the Practice of the Usage). Russkij jazyk i literatura v prostranstve mirovoj kul'tury. (7). Sankt-Peterburg.: MAPRJaL, 108-113.

Melerovich, A. M. Mokienko, V.M. (1997) Vvedenie (Introduction). Melerovich A.M., Mokienko V. M. Frazeologizmy v russkoj rechi. Slovar'. M.: Russkie slovari, 3-35.

Mokienko, V. M. (2010) Istoricheskaja frazeologija slavjanskih jazykov (Historical phraseology of Slavic languages). Teorija dijahronijske lingvistike. Belgrad, 103-129.

Ochkasova, M. R. (2005) O "Slovare gallicizmov v romane L. N. Tolstogo "Vojna i mir"» (About "The Dictionary of Gallicisms in the Novel by L. N. Tolstoy's "War and Peace"»). Leksika, leksikografija, terminografija v russkoj, amerikanskoj i drugih kul'turah. Ivanovo, 223224.

Rudnev, A. P. (1979) O ponjatii «kamernaja frazeologija» (na materiale frazeologii sem'i L.N. Tolstogo) (On the concept of "chamber phraseology" (based on the phraseology of the family of L.N. Tolstoy)). Problemy russkoj frazeologii. Tula: Tul'skij gos. ped. in-t im. L.N. Tolstogo, $75-82$.

Information about the author: Olga Lomakina - Doctor of Philological Sciences, professor of the Department of Foreign Languages, Faculty of Philology, the Peoples' Friendship University of Russia, Professor of the Department of Modern Russian Language at St. Tikhon's Orthodox Humanitarian University (Russia).

e-mail: rusoturisto07@mail.ru

Сведения об авторе: Ольга Валентиновна Ломакина - доктор филологических наук, профессор, университет Дружбы народов, Православный Свято-Тихоновский гуманитарный университет (Россия)

e-mail: rusoturisto07@mail.ru

Manuscript received: 11/20/2018

Accepted for publication: 01/25/2019

Рукопись получена: 11/20/2018

Принята к печати: 01/25/2019 